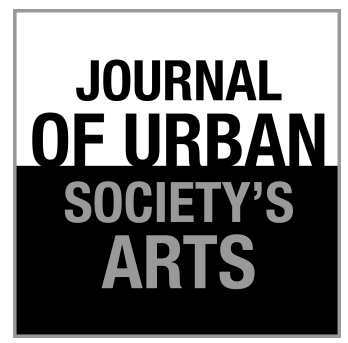

Volume 3 Nomor 1, April 2016: 1-9

\section{Transformasi Naskah Lakon Macbeth (1603-1607) Karya William Shakespeare Ke Film Throne of Blood atau Kumonosu-Jo (1957) Karya Akira Kurosawa}

Arinta Agustina

Jurusan Tata Kelola Seni, Fakultas Seni Rupa, Institut Seni Indonesia Yogyakarta Jln. Parangtritis Km 6,5 Bantul, Yogyakarta 55001

Tlp.081328723132, E-mail: dekatabin@gmail.com

\begin{abstract}
ABSTRAK
Karya sastra (naskah drama) yang ditransformasi ke film sudah tidak asing lagi bagi penontonnya. Film pada saat ditayangkan maka baik penulis karya sastra yang ditransformasi maupun pembacanya akan menemui banyak perbedaan. Perbedaan tersebut juga ditemukan dalam transformasi naskah Macbeth karya William Shakespeare ke film Throne of Blood atau Kumonosu-Jo karya Akira Kurosawa yang menjadi objek material penelitian ini. Kreativitas film terhadap karya sastra aslinya disebabkan adanya perbedaan yang mendasar antara karya sastra dan film, yakni medium. Karya sastra dalam hal ini menggunakan medium bahasa, sedangkan film menggunakan medium gambar dan suara. Terdapat suatu peristiwa tertentu yang dapat dimunculkan dengan baik pada karya sastra, tetapi tidak dapat dimunculkan dalam film, atau sebaliknya. Penelitian ini membatasi pada perbedaan kernel dan satelit film terhadap karya sastra aslinya. Perubahan fungsi yang menyebabkan perbedaan alur tersebut dianalisis menggunakan teori intertekstual. Hasil penelitian menunjukkan bahwa jumlah kernel dan satelit film lebih sedikit dibandingkan film karena tuntutan durasi. Film banyak memberikan variasi setting waktu dan tempat ataupun perubahan berupa penambahan tokoh dan alur sekaligus mengadakan penghilangan tokoh ataupun alur yang tidak memberikan peran penting dalam perkembangan penceritaan. Hasil penelitian juga menunjukkan adanya perubahan fungsi yang menghasilkan perbedaan alur antara karya sastra dan film.
\end{abstract}

Kata kunci: transformasi, Macbeth, Shakespeare, ekranisasi

\begin{abstract}
The Text Transformation of Macbeth (1603-1607) by William Shakespeare into the Film of Throne of Blood or Kumonosu-Jo (1957) by Akira Kuroswa. The transformation from the play to film is one of the common literary works. The writer of the play and the readers of the literary, however, face many differences in the film as the result of transformation process. These differences are also found at both; the play of Macbeth by William Shakespeare and the film of Throne of Blood by Akira Kurosawa. These two literary works are the objects of material in this research. The basic differences between a play and film are that each has its own medium. The medium of literary work is the language, meanwhile the media of film are pictures and music. Thus, there could be a certain plot appeared in a film but not in a literary work or vice versa. Furthermore; this research is merely limited on the differences of kernel and satellite toward the play and film. Eventually, the various changes of the function lead to the differences in plot. These changes of the function which lead to the differences are analyzed by making use of intertextuality theory. The result of this research indicates that the number of kernel and satellite of film is fewer than the one of literary. It happens because of the limited duration of the time. Eventually, there are many variations of setting of time, of place, and of participants. Moreover, the final result of this research
\end{abstract}


is that there are several changes of function which lead to the plot differences of both in literary works and film.

Keywords: transformation, Macbeth, Shakespeare, ekranisasi

\section{Pendahuluan}

Fenomena transformasi karya sastra ke film telah terjadi sejak beberapa dekade. Sejumlah besar film yang sukses, khususnya dari segi jumlah penonton dan apresiasi masyarakat, merupakan film yang diangkat atau ditransformasi dari karya sastra, khususnya novel atau naskah lakon. Dalam sejarah perfilman dunia, sebut saja Hollywood, hampir lebih dari delapan puluh persen skenario film dan televisi berasal dari adaptasi (Krevollin, 2003:11-14). Beberapa judul karya adaptasi yang telah ditransformasi ke dalam bentuk film, antara lain Romeo and Juliet, Hamlet, King Lear, karya Shakespeare, The Lord of the Rings karya Tolkien, dan Harry Potter karya J.K. Rowling. Transformasi karya sastra ke film di Indonesia dalam hal ini telah dimulai sejak tahun 70-an. Film dan sinetron yang juga hasil transformasi dari karya sastra atau novel antara lain Salah Asuhan, Siti Nurbaya, Di Bawah Lindungan Ka'bah, hingga ke film terbaru pemenang Piala Citra tahun 2011, Sang Penari, karya sutradara Ifa Isfansyah yang diangkat dari novel Ronggeng Dukuh Paruk karya Ahmad Tohari.

Transformasi adalah bagian yang lebih khusus dari adaptasi, karena menitikberatkan pada sebuah proses perubahan bentuk sebagai hasil kerja. Berkaitan dengan ini, akan terjadi alih wahana menurut Damono (2005) yang merupakan sebuah proses perubahan dari satu jenis kesenian ke dalam jenis kesenian lain. Alih wahana yang dimaksudkan di sini tentu saja berbeda dengan terjemahan. Di dalam alih wahana lebih lanjut disebutkan bahwa akan terjadi perubahan. Dalam hal ini akan tampak perbedaan antara karya yang satu dan karya hasil alih wahana tersebut. Alih wahana novel ke film misalnya, tokoh, latar, alur, dialog, dan lain-lain harus diubah sedemikian rupa sehingga sesuai dengan keperluan jenis kesenian lain.

Perbedaan dunia, dunia kata dan dunia gambar, yang dimiliki oleh dua media sastra dan film, tentu saja akan menghasilkan sesuatu yang berbeda. Perbedaan ini selain dipengaruhi oleh keterbatasan yang dimiliki masing-masing media maka perubahan bentuk dari novel ke film menurut Bluestone (1957) juga dipengaruhi oleh adanya proses resepsi, pembacaan, sutradara atau penulis skenario terhadap novel tersebut. Resepsi dalam hal ini tidak dapat lepas dari interpretasi dan termasuk juga ideologi dan tujuan, intensi, pesan, misi, dan keinginan sutradara ataupun penulis skenario. Kompleksitas ini akan sangat dipengaruhi oleh jiwa zaman, fenomena sosial yang berkembang, dan sosial masyarakat penerimanya. Dalam kondisi demikian sangat mungkin terjadi munculnya perbedaan ideologi antara novel dan film.

Transformasi dari karya sastra ke bentuk film dikenal dengan istilah ekranisasi. Ekranisasi menurut Eneste (1991) adalah suatu proses pelayarputihan atau pemindahan/pengangkatan sebuah novel ke dalam film. Istilah ini berasal dari bahasa Prancis, écran yang berarti 'layar'. Istilah lain selain ekranisasi yang menyatakan proses transformasi dari karya sastra ke film ada pula istilah lain, yaitu filmisasi. Di dalam karya sastra, segalanya diungkapkan dengan kata-kata. Pengilustrasian dan penggambaran dilukiskan dengan gambar, sedangkan dalam film, ilustrasi dan gambaran diwujudkan melalui gambar. Gambar di sini bukan hanya gambar mati, melainkan gambar hidup yang bisa ditonton secara langsung, menghadirkan sesuatu rangkaian peristiwa yang langsung pula. Ekranisasi sebenarnya adalah suatu pengubahan wahana dari kata-kata menjadi wahana gambar. Waktu yang dibutuhkan untuk menikmati atau membaca karya sastra tentu saja berbeda dengan waktu yang dibutuhkan untuk menikmati atau menonton film. Waktu untuk membaca karya sastra lebih longgar, lebih luas, sedangkan dalam film, waktu penikmatannya cenderung lebih terbatas. Keadaan tersebut tentu menjadi faktor 
yang penting untuk dipertimbangkan dalam transformasi karya sastra menjadi film. Keadaan ini pula yang kemudian menuntut para sineas melakukan kreasi-kreasi dalam proses transformasi. Faktor yang lain adalah tujuan para sineas dalam memfilmkan karya sastra tersebut (Hutcheon 2003).

Bahasa sebagai medium karya sastra memiliki sifat keterbukaan pada imajinasi pengarang. Proses mental lebih banyak terjadi dalam hal ini. Bahasa yang digunakan memungkinkan untuk memberi ruang yang luas bagi pembaca untuk menafsir dan mengimajinasi segala sesuatu yang diungkapkan oleh teks sastra tersebut (Kernodle 1967). Media gambar (audiovisual) sementara itu memiliki keterbatasan untuk semua itu. Gambar yang disajikan menjadi satu bentuk absolut yang bersifat paket. Penonton menerima gambar tersebut dan hampir tidak tersedia ruang baginya untuk mengimajinasikan tiap-tiap bagian yang ditontonnya. Faktor lain yang berpengaruh adalah durasi waktu dalam penikmatan film. Terbatasnya waktu memberikan pengaruh tersendiri dalam proses penerimaan dan pembayangan. Oleh karena itu, selain transformasi bentuk, ekranisasi juga merupakan transformasi hasil kerja.

Penelitian dengan objek material naskah Macbeth yang ditransformasi ke film sejauh ini belum peneliti temukan. Terdapat beberapa penelitian yang menggunakan kajian ekranisasi yang sudah dilakukan, antara lain "Transformasi Novel Ca Bau Khan ke Bentuk Film: Analisis Ekranisasi" (Rokhani, 2008) yang menitikberatkan pada perubahan fungsi yang terjadi dari novel ke film adaptasinya.

Penelitian yang lain adalah "Transformasi Novel REBECCA (1938) Karya Dadhne Du Maurier ke Bentuk Film REBECCA (1940) Karya Alfred Hitchcock: Analisis Ekranisasi” (Setyorini, 2009). Penelitian ini dibatasi pada perbedaan tokoh Kernel dan Satelit dalam film terhadap novel aslinya sehingga terlihat perbedaan alur film terhadap novel aslinya.

Kajian Ekranisasi juga dilakukan oleh Suseno (2009) dalam penelitian "Transformasi Politis Filmisasi Sastra Indonesia: Kajian Ekranisasi Cerpen Lintah dan Melukis Jendela ke Dalam Film
Mereka Bilang Saya Monyet Karya Djenar Mahesa Ayu dalam Perspektif Posmodernisme Hutcheon”. Keunikan dalam transformasi tersebut adalah dua ke dalam satu, yaitu dua cerita ke dalam satu cerita. Hasilnya adalah sebuah film postmodern dan kaya akan perubahan signifikan serta mengkaji aspek ideologis-politis perubahan tersebut.

Penelitian sejenis dilakukan oleh Wahyuningsih (2007) yang meneliti "Struktur Alur Drama Tragedi William Shakespeare dan Stuktur Alur Ketoprak: Sebuah Studi Banding". Penelitian ini menekankan perbandingan struktur alur yang terdapat dalam drama-drama tragedi karya Shakespeare dengan mengambil sampel antara lain Romeo and Juliet, King Lear, dan Hamlet dibandingkan dengan lakon ketoprak Mataraman.

Metode yang digunakan dalam penelitian ini adalah metode deskriptif analisis dan komparatif, yaitu dengan cara mendeskripsi fakta-fakta teks dan hasil analisis terhadap fakta teks naskah dan film, kemudian membuat perbandingan di antara kedua objek tersebut (Katarina Rima Melati 2014). Secara etimologis deskripsi dan analisis berarti menguraikan, sedangkan komparatif artinya membandingkan. Penelitian ini juga menggunakan metode penelitian kepustakaan (library research) terhadap naskah lakon Macbeth dan film Throne of Blood sebagai objek material kajian. Naskah lakon ini kemudian ditempatkan sebagai sebuah sistem dalam posisi yang imbang dan sejajar, yaitu meletakkan keduanya sebagai suatu struktur naratif sehingga membuat sistem sastra dan film dapat dianalisis. Struktur naratif dibagi menjadi dua, yaitu cerita atau isi, dan wacana atau ekspresi, bentuk naratif dapat berupa gambar dan musik. Dalam struktur naratif disebutkan juga bahwa manifestasi dari wacana dapat berbentuk sinematik atau film. Film ini terdiri atas gambar dan musik, sehingga film dapat dianalisis sebagai suatu sistem naratif. Tindakan selanjutnya adalah membandingkan cerita dan penokohan antara naskah Macbeth dengan film Throne of Blood sehingga diketahui persamaan, perbedaan, dan variasi-variasi dari perubahan yang terjadi di dalamnya.

Pemahaman secara intertekstual bertujuan untuk menggali secara maksimal makna-makna yang terkandung dalam sebuah teks. Analisis 
dilakukan dengan cara menemukan hubunganhubungan bermakna di antara dua teks. Teks-teks dikerangkakan sebagai interteks tidak terbatas sebagai persamaan genre, interteks memberikan kemungkinan yang seluas-luasnya bagi peneliti untuk menemukan hypogram. Hubungan yang dimaksud tidak semata-mata sebagai persamaan, melainkan juga sebaliknya sebagai pertentangan, baik sebagai parodi maupun negasi (Kartika 2015).

Penelitian ini diharapkan dapat memberikan pengayaan mengenai karya William Shakespeare, yaitu naskah lakon berjudul Macbeth yang telah mengalami perubahan bentuk melalui medium lain berupa audiovisual dalam film dengan judul yang berbeda yakni Throne of Blood atau Komunosu-Jo. Pengayaan tersebut diharapkan mampu mempertajam materi dan proses kegiatan belajar mengajar dalam kelas Film Drama III yang membahas film adaptasi, serta dapat menumbuhkan wacana, apresiasi, dan penghargaan masyarakat terhadap hasil dan bentuk karya seni adaptasi, baik berupa karya-karya sastra maupun film.

\section{Hasil Penelitian dan Pembahasan}

Dalam menganalisis naskah Macbeth yang diadaptasi dan film Throne of Blood sebagai hasil adaptasinya adalah dengan menempatkan keduanya sebagai sebuah sistem sastra dan sistem film. Sistem yang dianalisis adalah alur cerita keduanya, ditinjau dari kernel dan satelitnya sehingga diperoleh perubahan fungsi yang terjadi dalam film. Perubahan fungsi itulah yang menghasilkan beragam perbedaan antara kedua karya sastra tersebut dan merupakan proses pentransformasian atau ekranisasi. Proses telaah sistem sastra dan sistem film difokuskan pada kernel dan satelit sastra dan film (Chatman 1978). Chatman menempatkan novel dan film pada posisi imbang dan sejajar, yaitu meletakkan keduanya sebagai suatu struktur naratif. Hal itulah yang menyebabkan sistem sastra dan sistem film dapat dianalisis dengan mempergunakan kaidah masingmasing. Hasil analisis struktur naratif selanjutnya dapat dibandingkan untuk melihat perubahan fungsi yang terjadi melalui tinjauan intertekstual film terhadap karya sastra aslinya.
Proses di atas muncul dalam alur kerja film Throne of Blood karya Akira Kurosawa yang diangkat dari naskah lakon Macbeth karya William Shakespeare. Film karya sutradara Akira Kurosawa asal Jepang ini dianggap oleh banyak pengamat film sebagai salah satu film adaptasi yang sukses dalam menafsirkan dan menerjemahkan naskah Macbeth ke dalam bentuk dan budaya yang berbeda. Throne of Blood merupakan sebuah proses adaptasi yang ditransposisi dari bahasa Inggris ke konteks masyarakat dan budaya Jepang. Kurosawa membuat versi sinematik dari Jepang dan bukan sastra klasik Eropa. Akting para pemainnya menggunakan teknik bergaya teater Noh (teater tradisi Jepang). Film ini dibuat pada tahun 1956 dan dirilis pada Januari 1957 dan mendapat respons luar biasa di Amerika dan Eropa.

Akira Kurosawa adalah salah satu sutradara besar dalam dunia film dan teater yang berasal dari asia (Jepang) di mana yang karya-karyanya banyak memberikan pengaruh dan inspirasi kepada sineas-sineas terkenal dunia, seperti Satyajit Ray (India), John Woo (Hongkong), dan Steven Spielberg (Amerika). Penghargaan internasional telah diraihnya termasuk Piala Oscar. Menurut beberapa pengamat film, kepiawaiannya mengolah budaya Jepang dengan sangat kuat sebagai tempat asal kelahirannya dalam film sampai saat ini belum ada tandingannya.

\section{a. Naskah Macbeth}

Tragedi Macbeth adalah sebuah drama yang ditulis oleh William Shakespeare sebagai tragedi terpendek yang dihasilkannya dan diyakini ditulis antara tahun 1603 dan 1607. Menurut catatan ahli sejarah, drama ini pertama kali dipertunjukkan pada April 1611 dan dipublikasikan perdana dalam bentuk Folio di tahun 1623. Alur cerita adalah alur maju yang penuh dengan ketegangan, yang dimulai dari Act I sampai Act V dengan 28 scene. Bercerita tentang seorang jenderal bernama Macbeth di bawah pemerintahan Raja Skotlandia Duncan I. Latar cerita mengambil tempat di Skotlandia, Inggris, dan Irlandia.

Tokoh-tokoh yang menghiasi drama Macbeth antara lain adalah Duncan I (Raja Skotlandia), Malcolm (anak sulung Raja Duncan), Donalbain 
(anak bungsu Raja Duncan), Macbeth (jenderal dalam pasukan Raja Duncan, awalnya penguasa daerah Glamis, kemudian diangkat menjadi penguasa daerah Cawdor, lalu menjadi Raja Skotlandia), Lady Macbeth (istri Macbeth, dan kemudian menjadi Ratu Skotlandia), Banquo (sahabat Macbeth dan jenderal dalam pasukan Raja Duncan), Fleance (anak Banquo), Macduff (penguasa daerah Fife), dan Lady Macduff (istri Macduff), dan Tiga Wanita Penyihir.

Babak pertama dimulai dengan gemuruh petir dan kilat ketika Tiga Penyihir Wanita memutuskan bahwa pertemuan mereka yang berikutnya adalah dengan Macbeth. Adegan berikutnya menggambarkan seorang sersan yang terluka melapor kepada Raja Duncan I dari Skotlandia bahwa jenderal-jenderalnya, Macbeth dan Banquo, berhasil mengalahkan pasukan sekutu Norwegia dan Irlandia yang dipimpin oleh McDonwald si pengkhianat. Macbeth, sebagai prajurit setia raja, dipuji atas keberanian dan kecakapannya.

Macbeth dan Banquo kemudian bertemu dengan Tiga Penyihir Wanita yang meramalkan bahwa Macbeth yang sedang menjadi penguasa daerah Glamis akan menjadi penguasa di daerah Cawdor dan kemudian menjadi Raja Skotlandia. Banquo disebut akan melahirkan garis keturunan raja-raja mekipun ia sendiri tidak akan menempati posisi tersebut. Peristiwa selanjutnya adalah turunnya titah Raja Duncan I yang menganugerahkan gelar Penguasa Daerah Cawdor kepada Macbeth. Ramalan pertama yang terpenuhi membuat Macbeth mulai percaya dan berambisi menjadi raja. Lady Macbeth mendesak suaminya untuk membunuh raja. Pada saat Raja Duncan I menginap di kastil mereka di Inverness, Macbeth membunuhnya dan menyalahkan pengawal raja sebagai pembunuhnya. Dalam hal ini tidak semua orang memercayai perkataan Macbeth, salah satunya adalah Macduff, penguasa daerah Fife yang setia kepada Raja Duncan I. Macduff tidak mengungkapkan kecurigaannya. Macbeth pun akhirnya mengklaim tahta atas posisinya sebagai prajurit kepercayaan raja dengan mulus karena kedua putra Raja Duncan I, Malcolm dan Donalbain, melarikan diri dan bersembunyi ke Inggris dan Irlandia akibat takut dibunuh.
Macbeth dan istrinya setelah menjadi raja dan ratu tetap tidak bisa merasa damai. Macbeth masih mengkhawatirkan ramalan Tiga Penyihir Wanita mengenai Banquo yang diramalkan akan menghasilkan keturunan raja-raja. Macbeth pun menyuruh pembunuh untuk menghabisi Banquo. Lady Macbeth sementara itu berjuang melawan rasa bersalahnya hingga mengalami gangguan mental di mana dalam bayangannya Lady Macbeth selalu melihat tangannya bersimbah darah. Kekuasaan Macbeth yang tiran kemudian runtuh setelah Malcolm, putra Raja Duncan I, dan Macduff memimpin pasukan untuk menggulingkannya. Pada akhirnya Malcolm pun menjadi raja.

Dalam naskah ini kekuatan kata menjadi utama untuk membangun aspek dramatik cerita. Dialog dan karakter yang muncul menciptakan situasi yang paradoksal sehingga menghasilkan konflik, baik itu konflik moral dan emosional yang terjadi dalam diri tokoh maupun konflik fisikal yang terjadi sebagai akibat dari sebuah interaksi dari aksi dan reaksi.

\section{b. Film Throne of Blood atau Kumonosa-Jo}

Film ini mengambil setting pada masa kepemimpinan Oda, ketika masih banyak daerah yang saling berebut kekuasaan, meskipun tahun pembuatan film tersebut adalah tahun 1957 yaitu setelah berakhirnya Perang Dunia II ketika Jepang menjadi pihak yang dikalahkan. Film Throne of Blood adalah salah satu karya Akira Kurosawa yang cukup menarik banyak perhatian para pemerhati film.

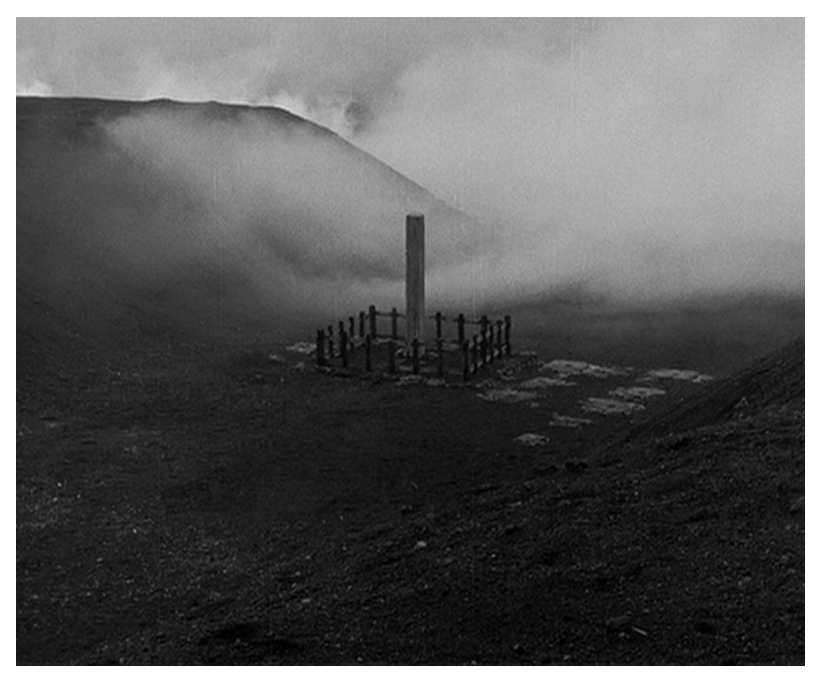

Gambar 1. Adegan awal Throne of Blood. 
Film dimulai dengan gambar sebuah lembah yang berkabut. Perlahan-lahan kabut menghilang. Tampak beberapa gundukan tanah yang terlihat seperti kuburan, dan sebuah bangunan yang berdiri terlihat seperti sebuah monumen. Peristiwa selanjutnya muncul seorang prajurit menunggang kuda dengan tergopoh-gopoh mendekati sebuah bangunan benteng. Pada saat berada di depan pintu gerbang yang tertutup sang prajurit berusaha mengetuk dengan keras dan tergesa-gesa. Kamera terfokus pada prajurit yang mengetuk pintu gerbang. Prajurit masuk ke dalam benteng dan memberikan laporan kepada Raja Tsuzuki. Prajurit tersebut melaporkan kekalahan pasukannya di benteng utara. Prajurit yang lain kemudian membawa berita kemenangan dari pasukan yang dipimpin oleh Jenderal Washizu yang diperankan oleh Toshiro Mifune, seorang komandan Samurai dari Raja Tsuzuki. Dalam peristiwa tersebut, setelah mengalahkan musuh dalam pertempuran bersama Miki, maka dalam perjalanan melalui hutan menuju istana, kedua orang tersebut bertemu roh yang meramalkan masa depan kedua orang tersebut. Roh tersebut mengatakan kepada kedua orang tersebut bahwa hari ini Jenderal Washizu akan diberi anugerah Benteng Utara. Roh tersebut kemudian meramalkan bahwa Washizu akhirnya akan menjadi raja, dan roh itu juga mengatakan kepada Miki bahwa anak keturunannya kelak akan menjadi penguasa.

Sesampainya mereka di istana, Raja Tsuzuki memberi anugerah kepada kedua orang tersebut, seperti ramalan roh tersebut. Pada saat di rumah, Jenderal Washizu membahas ini dengan Asaji,

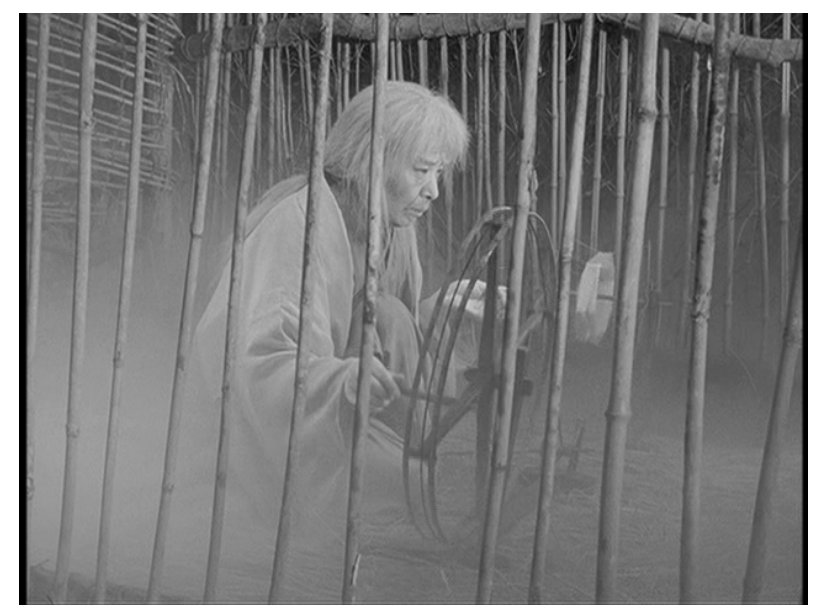

Gambar 2. Adegan penyihir. istrinya, yang berambisi untuk membuat bagian kedua dari ramalannya terbukti, dengan membunuh Raja Tsuzuki ketika datang berkunjung. Jenderal Washizu dan istrinya akhirnya berhasil membunuh Raja. Asaji mengambil tombak berdarah dari tangan suaminya, dan meletakkannya di tangan salah satu dari tiga penjaga yang tertidur di depan kamar Raja. Jenderal Washizu kemudian berteriak "Pembunuh!" kepada penjaga tersebut sebelum ia sadar dan memiliki kesempatan untuk membela diri yang tidak bersalah.

Kedua anak Tsuzuki, Kunimaru dan Noriyasu mencurigai Washizu sebagai pengkhianat dan pembunuh. Kunimaru dan Noriyasu mencoba untuk memperingatkan Miki yang menolak untuk percaya dengan apa yang kedua anak Tsuzuki katakan tentang Washizu yang merupakan temannya. Washizu meskipun tidak yakin terhadap loyalitas Miki namun Washizu ingin memercayai temannya dan Washizu berencana untuk membiarkan anak Miki menjadi ahli warisnya karena Washizu dan Asaji tidak mampu melahirkan anak sendiri. Washizu berencana akan mengumumkan tentang keputusannya dalam perjamuan besar. Sebelum peristiwa itu terjadi Asaji mengatakan kepadanya bahwa Asaji hamil dan membuat Washizu kebingungan tentang ahli warisnya. Washizu pada akhirnya memutuskan untuk menyuruh pembunuh melenyapkan temannya yaitu Miki. Selama perjamuan Washizu sangat gelisah dan mulai kehilangan kendali. Dalam kepanikan delusinya tersebut Washizu mengungkapkan pengkhianatannya kepada semua orang dengan berseru bahwa Washizu bersedia untuk membunuh Miki untuk

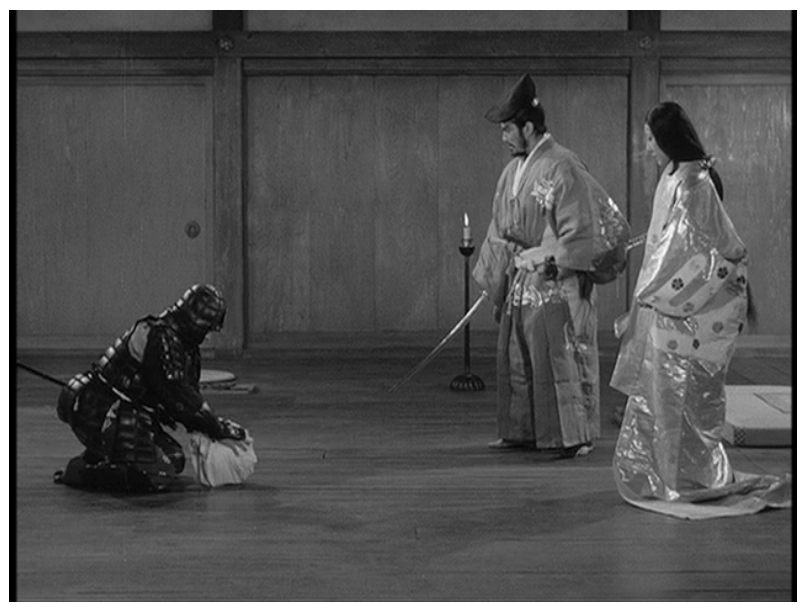

Gambar 3. Adegan Jenderal Washizu dan Asaji, istrinya. 
kedua kalinya. Asaji berusaha untuk menutupi kesalahan Washizu, dengan mengatakan kepada para tamu bahwa suaminya mabuk dan harus segera beristirahat. Kejadian selanjurnya yaitu salah satu pembunuh suruhan Washizu tiba dengan kepala Miki yang terpenggal. Penjaga itu melaporkan kepada Washizu dan istrinya bahwa anak Miki lolos.

Melihat situasi yang kacau dan mengancam membuat Asaji syok dan akhirnya mengalami keguguran. Dalam situasi yang serba sulit maka Washizu kembali ke hutan untuk memanggil roh. Washizu menanyakan bagaimana nasib Washizu dan istrinya selanjutnya. Roh mengatakan kepadanya bahwa Washizu tidak akan dikalahkan kecuali oleh pohon-pohon yang naik dari hutan ke benteng. Washizu percaya bahwa ini adalah yang tidak mungkin dan yakin akan kemenangannya. Washizu kemudian menemukan Asaji dalam kekatatonik dan mencoba untuk mencuci dan membersihkan bau busuk darah yang imajiner dari tangannya. Washizu sangat ketakutan terhadap kejahatannya sendiri. Pada saat itu terdengar suara pasukannya bergerak di luar ruangan. Washizu menyelidiki dan diberi tahu oleh seorang prajurit bahwa pohon-pohon hutan "telah naik ke benteng untuk menyerang kami!" Washizu mencoba memerintahkan pasukannya untuk menyerang, tetapi pasukannya tetap terdiam. Para prajurit itu pada akhirnya berpaling dari Washizu dan mulai menembakkan panah kepada Washizu sebagai balas dendam atas tindakan pengkhianatan Washizu. Washizu akhirnya meninggal akibat luka-lukanya ketika musuh-musuhnya mendekati gerbang istana.

\section{c. Perbandingan Alur Cerita Antara Film dan Naskah}

Perbandingan alur cerita dari naskah Macbeth dengan film Throne of Blood sebenarnya tidaklah terlalu jauh. Di awal naskah dimulai dengan suara petir yang bergemuruh dan kilat yang menyambar, masuklah tiga orang wanita penyihir. Di awal film dimulai dengan sebuah pemandangan lembah yang ditutupi oleh kabut tebal yang perlahanlahan pergi, seorang prajurit berkuda, memacu kudanya hingga ke gerbang Benteng. Dalam film sosok penyihir berganti menjadi sosok roh seorang perempuan yang sedang memintal benang di dalam hutan. Gambaran yang ingin disampaikan secara garis besar adalah sebuah suasana yang mencekam penuh ketegangan. Perbedaan yang terjadi sebagai akibat perubahan fungsi pada film terhadap naskah aslinya meliputi perubahan karena penyesuaian, penghilangan, perluasan atau pengembangan teks serta pengambilan intisari dari teks sebelumnya.

Saat Macbeth menjadi gelisah dan bingung dengan rencana dan ambisinya terungkap lewat monolognya yang cukup panjang. Dalam film, kegugupan dan kekacauan pikiran Washizu dimunculkan dengan adegan Washizu berjalan hilir mudik di dalam kamarnya, tanpa berdialog, tetapi gestur dan ekspresi wajahnya terlihat kaku dan tegang. Intensitas akting yang penuh ketegangan ini membuat suasana terlihat mencekam. Di bagian lain di film adalah saat Asaji menjadi terganggu mentalnya disebabkan oleh keguguran yang dialaminya dan kejahatan yang telah dilakukannya yang dibayangi perasaan seakan-akan tangannya selalu dilumuri oleh darah sehingga Asaji selalu mencuci tangannya. Dalam naskah, lewat dialognya Lady Macbeth merasa ketakutan dan seolaholah melihat tangannya selalu menempel darah sehingga Lady Macbeth harus selalu menggosokgosokkannya agar dapat hilang. Kondisi Lady Macbeth semakin lama semakin mengkhawatirkan sehingga Lady Macbeth terlihat seperti orang yang kehilangan akal sehatnya dan akhirnya wafat.

Perpindahan budaya yang dilakukan oleh Kurosawa menyebabkan beberapa karakteristik dari naskah Macbeth mengalami perubahan fungsi dan makna. Perubahan fungsi dan makna ini dapat dilihat antara lain dengan senjata yang menjadi pembunuh tokoh utamanya. Dalam film, Washizu mati dengan tubuh yang ditembusi anak panah sedangkan dalam naskah aslinya Macbeth mati karena tebasan pedang di tubuhnya. Perbedaan terjadi sebagai akibat perubahan fungsi yang terjadi dalam film terhadap naskah drama sebagai hipogramnya meliputi modifikasi (perubahan karena penyesuaian), haplologi (penghilangan), ekspansi (perluasan atau pengembangan teks) serta ekserp (pengambilan intisari dari teks sebelumnya). Penerapan prinsip-prinsip intertekstual tersebut adalah dalam rangka mencapai perubahan-perubahan fungsi yang terjadi dalam film hasil transformasi. 
Terdapat variasi di sana-sini dari cerita aslinya, namun Kurosawa cukup berpegang erat dengan ade-gan yang akan mudah dikenali oleh orangoramg yang pernah membaca Macbeth, misalnya adegan ketika Asaji (Lady Macbeth) mencuci tangannya berulang-ulang karena merasa ada noda darah yang tidak mau hilang. Hal ini juga terlihat ketika prajurit datang menyerang, Washizu sambil membawa dahan-dahan pohon dari hutan. Keadaan ini memberi kesan bahwa seluruh hutan datang ke istana Washizu. Film Throne of Blood ini mengambil setting pada masa kepemimpinan Oda, ketika masih banyak daerah yang saling berebut kekuasaan, meskipun tahun pembuatan film tersebut adalah tahun 1957 yaitu setelah berakhirnya Perang Dunia II ketika Jepang menjadi pihak yang dikalahkan.

Naskah Macbeth dibuat pada sekitar tahun 1603-1607 pada masa pemerintahan Inggris, Skotlandia dan sekitarnya yang bersifat kerajaan. Akira Kurosawa pada akhirnya masih bisa menangkap kontekstualitas peristiwa yang terjadi pada dua era yang sungguh jauh pautan jaraknya. Ambisi terhadap kekuasaan pada masa kapan pun masih dapat terjadi dan mampu membuat seorang ksatria yang terbaik sekalipun menjadi hancur. Kondisi ini terjadi pada Jenderal Washizu dan Jenderal Macbeth sebagai sosok yang paling dihormati dan disegani atas keberanian dan kehormatannya baik oleh bawahan, sahabat, maupun musuh-musuh kedua orang tersebut. Keadaan yang menarik dari kedua versi cerita ini adalah tentang sebuah kekuatan yang di luar kemampuan rasionalitas manusia ternyata mampu membuat cara berpikir dan tujuan seorang menjadi tidak rasional.

\section{Simpulan}

Hasil penelitian menunjukkan bahwa jumlah kernel dan satelit film lebih sedikit dibandingkan naskah karena tuntutan durasi. Film banyak memberikan variasi setting waktu dan tempat serta perubahan berupa penambahan tokoh dan alur sekaligus mengadakan penghilangan tokoh maupun alur yang tidak memberikan peran penting dalam perkembangan penceritaan. Hasil penelitian juga menunjukkan adanya perubahan fungsi yang menghasilkan perbedaan alur antara novel dan film. Perubahan fungsi tersebut menerapkan prinsip transformasi atau ekranisasi. Proses kerja transformasi bukanlah suatu proses yang tidak mudah, namun kenyataannya banyak sekali penulis ataupun sutradara teater yang terusmenerus memanfaatkan karya sastra sebagai sumber inspirasinya.

Perbedaan media mengharuskan penulis dan sutradara menciptakan berbagai cara untuk menyesuaikan karya barunya dengan tuntutan media yang berubah. Perbedaan nyata antara keduanya adalah pada penggunaan bahasa. Dalam karya prosa, bahasa yang digunakan berupa tulisan yaitu pembaca memiliki ruang personal yang sangat imajinatif dalam meresepsi dan menginterpretasikan pembacaannya. Pembaca memiliki waktu yang tidak terbatas dalam menikmati karya tersebut. Situasi ini yang membedakan dengan bahasa pementasan. Bahasa pementasan adalah bahasa audio dan visual (gerak dan laku) yaitu penonton tidak lagi memiliki keleluasaan ruang personal dalam meresepsi dan menginterpretasi karena bahasa audiovisualnya telah dipilih dan diterjemahkan oleh sang sutradara di atas panggung, dan waktu penikmatan terhadap karya tersebut terbatas oleh durasi pertunjukan. Kedua bahasa tersebut memiliki kekuatan dan kelemahan masing-masing dalam berkomunikasi dengan penikmatnya.

Penelitian ini masih berfokus pada masalah struktur yang terdapat dalam naskah Macbeth dan film Throne of Blood dengan menggunakan sistem naratif yang menyejajarkan kedudukan keduanya. Dalam hal ini kiranya masih terlalu sempit objek yang dapat dianalisis, ekranisasi sendiri sebagai sebuah kajian keilmuan belumlah terlalu kokoh berdiri sebagai sebuah teori yang utuh. Kajian ini baru akan memberikan keluasan dan kekuatan sudut pandang jika dibantu dengan menggunakan perspektif keilmuan lainnya.

\section{Ucapan Terima Kasih}

Penulis menghaturkan terima kasih yang mendalam kepada (1) Lembaga Penelitian ISI Yogyakarta yang telah memberikan kucuran dana sehingga penelitian ini dapat terlaksana; (2) 
Drs. Koes Yuliadi, M.Hum. sebagai pembimbing penelitian.

\section{Kepustakaan}

Bluestone, G., 1957. Novels into Film. Berkeley: University of California Press.

Chatman, S., 1978. Story and Discourse; Narrative Structure in Film and Fiction. London: Cornell University Press.

Damono, S.D., 2005. Pegangan Penelitian Sastra Bandingan. Jakarta: Pusat Bahasa.

Eneste, P., 1991. Novel dan Film. Jakarta: Nusa Indah.
Hutcheon, L., 2003. From Page to Stage to Screen; The Age of Adaptation. Toronto: University of Toronto.

Kartika, B.A., 2015. "Mengapa Selalu Harus Perempuan: Suatu Konstruksi Urban Pemenjaraan Seksual Hingga Hegemoni Maskulinitas dalam Film Soekarno". Journal Of Urbarn Society's Arts, 2(1), p.35.

Katarina Rima Melati, 2014. Pendidikan sebagai Perekrut dalam Komunitas Terbayang: Analisa Wacana dalam Film Denias Senandung di atas Awan. Journal Of Urbarn Society's Arts, 1(2).

Kernodle, George R. 1967. Invitation to the Theatre. New York: Harcourt, Brace \& World, Inc. 